\title{
Adjusted-Productivity Growth for Resource Rents: Kuwait Oil Industry
}

\author{
Bassim Shebeb $^{1}$ \\ ${ }^{1}$ Acting Dean, Arab Open University, Kuwait \\ Correspondence : Dr. Bassim Shebeb, Arab Open University, P.O. Box 632, Al-Ardia, Kuwait
}

Received: January 11, 2016

Accepted: January 31, 2016

Available online: February 16, 2016

doi:10.11114/aef.v3i2.1386

URL: http://dx.doi.org/10.11114/aef.v3i2.1386

\begin{abstract}
Using the data from Kuwait oil industry for the period 2002-2012, this paper has attempted to answer the question how the incorporation of the exhaustible resource rent can affect the multifactor productivity (MFP) growth rate of an exhaustible resource extracting industry. As such it re-examines the notion of incorporating the exhaustible resource (oil) rents in the growth accounting. Such incorporation produces considerable different results compared to the results obtained from the classical growth accounting procedures. This implies that an appropriate growth model for an exhaustible resources-based industry (economy) should take into account the total resource rents to avoid any miscalculation (inaccuracy) in the growth rate of MFP.
\end{abstract}

Keywords: multifactor productivity, exhaustible resources, Hotelling and Ricardian rents

\section{Introduction}

Almost two decades ago Al-Ebraheem and Shebeb (1997) originally proposed and incorporated the stock depletion of an exhaustible resource in the growth accounting of an open economy. They have emphasized the importance of the incorporation because such incorporation makes a methodological contribution by addressing and measuring the effects of an exhaustible resources stock depletion and resource rent on multifactor productivity (MFP). This issue has been revisited recently by Schreyer et al. (2015).

For an economy based on exhaustible resources, identifying and measuring the contribution of the exhaustible resources are valuable in evaluating and understanding its growth. An increasing number of studies have been devoted in analyzing the effect of the stock depletion of an exhaustible resource on productivity growth measurement. Moreover, the existing studies have addressed the issue of how the resources rent could affect the growth rate of MFP in an exhaustible resource-based industry and/or economy.

In growth accounting model (framework), the main sources of the output growth are identified and their contributions are measured. The contribution of various factors of production to output growth is the prime concern of all studies related to growth. Due to recent developments, the observed productivity growth has been analytically decomposed into several important measures of economic performance. These measures are technical change, scale economies, productive and cost efficiency, and capacity utilization (Shebeb, 2002). However, the output growth is seen as a compound measure of two major components: Multifactor Productivity (MFP) and Factor-Intensities (FI). In this paper, the notion of incorporation the exhaustible resource (oil) rents in the growth accounting is re-examined in Kuwait oil industry with most recent data available over the time period from 2002 to 2012 . The Kuwaiti oil industry is defined to include all the territorial boundaries of Kuwait and its offshore areas that engage in the production of crude petroleum and natural gas. It is classified as a two-digit standards industrial classification (SIC-22).

\section{Meaning of Resource Rent}

The scarcity and differential rents which are known as the commencement notion of rents were presented by Hotelling (1931) and Ricardo (1951), respectively. Hotelling's main concern was the exhaustibility. He showed that it is socially desirable for the price of an exhaustible resource to be above its marginal extraction cost. This so-called Hotelling rent represents the economic effects of extracting one marginal unit of the resources stock at the current date on future extracting costs. Thus, Hotelling's rent can be seen as an additional cost that should be added to the costs of current extraction. On the other hand, the concern of the Ricardian "differential" rent was the quality (fertility) of the agricultural lands. However, Cairns (1986) has modified it to deal with the economics of exhaustible resources. That is, at the current price some mines or fields may cover all their extraction costs and command the so-called Ricardian rent, 
which is the excess of price over cost, while the marginal mine or field achieves zero economics profit. Thus, assuming that all oil fields are different in their geological characteristics only, then the world oil deposits would be heterogeneous in Ricardo's point of view. Furthermore, heterogeneity of oil fields may be present with, for example, viscosity, depth, location, and many other chemical and / or geological characteristics.

It follows that for a given oil price some oil producers would be able to cover all their extracting and processing costs and gain Ricardian rent, while others are just surviving (Miller, 1992). The point is that the extraction cost of some exhaustible resources should account for the two kinds of rents, namely, Ricardian and Hotelling.

The critical question in productivity modeling is whether the resource rent would fundamentally affect the estimated level of productivity growth. Thus, the objective of this study is to answer this question using the Kuwait oil industry. The answer to this question would show how critical it is for Kuwait to consider the rents of its exhaustible resource (oil) in any future growth-oriented studies.

\section{The Model}

The standard (traditional) productivity growth accounting needs to be adjusted to identify the impacts of inputs-fixity (capacity utilization), technical and non-technical inefficiency, and to the existence of non-constant return to scale (scale economies). Additional adjustment also may be required to recognize the impacts of the biases with respect to inputs-fixity and technical change (MFP). However, as mentioned above, this paper attempts to adjust the traditional productivity growth accounting for stock depletion (Hotelling's rent) and for the existence of relative extraction-cost advantages (Ricardian "differential" rent) in an exhaustible resource based industry, namely, Kuwait oil industry. Thus, both Hotelling's rent (economic depreciation of an exhaustible resource) and Ricardian rent are incorporated in the growth accounting of MFP in Kuwait oil industry. A growth accounting model is used in the measurement of the growth rate of gross output and the sources of its growth which are the MFP growth rate and the growth rate of inputs.

In this paper the rate of growth of aggregate production (gross output) is represented as a combination of the contributions of the growths of the respective production factors - physical capital (K), labor (L), intermediate inputs (M - energy, materials, and services), the exhaustible resource rents $(R)$, and technological change $\left(A_{t}\right)$. Note that $R$ may include both Hotelling's rent (dynamic rent) and the Ricardian rent (differential rent). A production function with Hicks-neutral technology is specified as:

$$
Q_{t}=A_{t} \psi\left(X_{i, t}\right)
$$

where $\mathrm{Q}_{t}$ is the real gross output at time $t, \mathrm{~A}_{t}$ is the technical change (multifactor productivity, MFP), and $\mathrm{X}_{\mathrm{i}, \mathrm{t}}, \mathrm{i}=\mathrm{K}, \mathrm{L}$, $\mathrm{M}$, and $\mathrm{R}$ are the real amount of the inputs at time. The underlying assumptions in formulating this production function are: the constant return to scale, Hicks's neutral technical change, and competitive inputs and output markets. Furthermore, for simplicity, additional economic and technical assumptions are also assumed which are homogeneity and non-durability of the exhaustible resource (oil), no exploration activity or cost, and no new discoveries. However, it should be noted that most of these assumptions are reasonably weak for Kuwait oil industry.

Conceptually, MFP growth indicates the change in output resulting from the shift of the production function. By differentiating it with respect to time, equation (1) can easily be transformed to growth equation as in equation (2):

$$
\frac{d Q / d t}{Q}=\frac{d A / d t}{A}+\sum_{i} \frac{\partial Q}{\partial X_{i, t}} \frac{X_{i, t}}{Q} \frac{d X_{i, t} / d t}{X_{i, t}}
$$

Therefore, the above growth equation decomposes the growth of output into two main components, namely, the growth of inputs and the growth of MFP (the unexplained part of the output growth). Equation (2) shows the rate of change of output as a sum of the rate of change in the MFP $[(\mathrm{dA} / \mathrm{dt}) / \mathrm{A}]$ and the weighted average of the rate of change in use of inputs. Exploiting the model's underlying assumptions including the assumption that the weights (shares) sum up to one, equation (2) can be written as:

$$
\frac{d Q / d t}{Q}=\frac{d A / d t}{A}+\sum_{i} S_{i} \frac{d X_{i, t} / d t}{X_{i, t}}, \text { and } \mathrm{S}_{\mathrm{i}}=\mathrm{C}_{\mathrm{i}} / \mathrm{P}_{\mathrm{Q}} \mathrm{Q},
$$

where $\mathrm{C}_{\mathrm{i}}$ is the total payment to the $\mathrm{i}^{\text {th }}$ input, where $\mathrm{i}=\mathrm{K}, \mathrm{L}, \mathrm{M}$, and $\mathrm{R}$ and $\mathrm{P}_{\mathrm{Q}}$ is the price of output (Q). Equation (3) is known as a divisia index. Thus, taking the natural $\log (\mathrm{In})$ for the inputs and output index numbers and using the average input shares, an approximation of the Tornqvist index number (Diewert and Nakamura, 2007, and Diewert, 
1976) and the $\mathrm{MFP}_{\text {adj }}$ growth rate can be presented as follows:

$$
\mathrm{MFP}_{a d j}=\ln \frac{A_{t}}{A_{t-1}}=\ln \frac{Q_{t}}{Q_{t-1}}-\sum_{i} \bar{S}_{i} \ln \frac{X_{i, t}}{X_{i, t-1}}, \text { where: } \overline{S_{i}}=0.5\left(S_{i, t}+S_{i, t-1}\right)
$$

Equation (4) - considered as Model-I - can be defined as the rate of $\mathrm{MFP}_{\text {adj }}$ growth [In (At/At-1)], i.e., the rates of growth of gross output, less the weighted average of the rate of growth of the inputs. This shows that $\mathrm{MFP}_{\text {adj }}$ can be seen as a deviation of the growth rate of output from the growth rate of inputs. One of the advantages of this method is that the Hicksian parameter $\left(\mathrm{A}_{t}\right)$ or (the growth rate of MFP) can be measured using price and quantity data. The MFP adj growth rate, however, is a valid measure of technological change $\left(A_{t}\right)$ only under the model's assumptions.

On the other hand, a growth model-II that does not consider the depletion of an exhaustible resource could be obtained based on a gross output production function with no resource rent and can be derived as in equation (5):

$$
\mathrm{MFP}=\ln \frac{A_{t}}{A_{t-1}}=\ln \frac{Q_{t}}{Q_{t-1}}-\sum_{i} \bar{S}_{i} \ln \frac{X_{i, t}}{X_{i, t-1}}, \quad \text { where: } \overline{S_{i}}=0.5\left(S_{i, t}+S_{i, t-1}\right)
$$

where input index $\mathrm{i}$ includes only $\mathrm{K}, \mathrm{L}$, and $\mathrm{M}$. Therefore, the significant impact of considering the exhaustible resource rents on the growth rate of MFP could easily be traced as: $\Omega=\mid$ MFP-MFP adj $\mid$.

\section{Data and Measurement}

Data used for this research were obtained from the publications of the Central Statistical Office, the official data source in Kuwait. The Compiled statistics related to the calendar years from the year 2002 to the year 2012. Specifically output and input data were collected from the National Accounts Statistics, while the data for the deflators were obtained from the Statistical Abstracts. The natural resources rents (Hotelling and Ricardian) are obtained by subtraction which is the output unit price net all costs of extraction.

In reference to the underlying assumptions of the growth accounting model, the total extraction and processing costs should be equal to the value of the gross output. It follows that the inputs shares (weights) can be obtained as the input-cost share in the output (current prices). Thus, theses share are as follows: the share of labor input in total factor payments is derived by expressing national accounts estimates of total compensation as a fraction of gross output at current factor cost; the share of intermediate-inputs is derived by expressing national accounts estimates of value of intermediate-inputs as a fraction of gross output at current factor cost; the share of capital is derived by expressing national accounts estimates of the value of capital consumption (depreciation) as a fraction of gross output at current factor cost; thus, the share of resource (rents) is taken to be the complement of the shares of labor, intermediate-inputs, and capital. Computing factor shares on the basis of the current market prices straighten the relative contributions of capital, labor, intermediate-inputs, and natural resources (oil and gas).

The wholesale price index (stage of processing) for production materials was used to obtain the real gross output and resource rents. For intermediate inputs, the wholesale price index (stage of processing) was used. The capital input was deflated by the wholesale price index (end-use) capital goods. Labor compensations were deflated by the consumer price index. Year $2007=100$ is the base year for all price deflators.

Table 1 shows an overall look on gross output (Q), inputs (extraction costs) in current prices and the resources (oil and gas) rents of Kuwait oil Industry. The total extraction costs that include labor compensation (L), cost of capital services $(\mathrm{K})$, cost of intermediate-inputs, including energy, materials, and services $(\mathrm{M})$, and the rents (R) for land (natural resources; oil and gas). (Note 1)

From Table 1 we can see that there was a significant drop in production in 2009. However, despite this significant drop in output, the labor compensations (costs) continued to grow. Table 1 also shows the resources rent as a percentage of oil output. The resource rents are equal to the gross output minus the all costs of extraction. However, a large portion of the resource rents could be attributed to Ricardian conception on land rent. (Note 2) On average, resource rents represent about $94.5 \%$ of the reported gross output. It is clearly that the resource rent could generate a significant effect on the measurement of MFP growth in Kuwait oil industry. 
Table 1. Gross output and inputs: Kuwait oil industry, 2001 - 2012

\begin{tabular}{|c|c|c|c|c|c|c|}
\hline \multicolumn{7}{|c|}{ In 000 Kuwaiti Dinars - KD, KD $1 \cong \$ 3.35$ - Current Prices } \\
\hline \multirow{3}{*}{ YEAR } & \multirow{3}{*}{$\begin{array}{c}\text { Output } \\
\text { Q }\end{array}$} & \multicolumn{4}{|c|}{ Inputs (extraction cost) } & \multirow{3}{*}{$\begin{array}{c}\mathrm{R} / \mathrm{Q} \\
\%\end{array}$} \\
\hline & & \multirow{2}{*}{$\begin{array}{c}\text { Capital } \\
\text { Services } \\
\text { K }\end{array}$} & \multirow{2}{*}{$\begin{array}{l}\text { Labor } \\
\text { L }\end{array}$} & \multirow{2}{*}{$\begin{array}{l}\text { intermediate-in } \\
\text { puts } \\
\text { M }\end{array}$} & \multirow{2}{*}{$\begin{array}{c}\text { Resource Rents } \\
\text { R }\end{array}$} & \\
\hline & & & & & & \\
\hline 2002 & $4,492,284$ & 74,676 & 134,165 & 83,066 & $4,200,377$ & 93.50 \\
\hline 2003 & $5,906,969$ & 125,605 & 145,234 & 109,209 & $5,526,921$ & 93.57 \\
\hline 2004 & $7,969,412$ & 137,201 & 167,957 & 147,357 & $7,516,897$ & 94.32 \\
\hline 2005 & $12,474,544$ & 152,298 & 221,244 & 241,792 & $11,859,210$ & 95.07 \\
\hline 2006 & $16,783,927$ & 160,743 & 224,637 & 305,634 & $16,092,913$ & 95.88 \\
\hline 2007 & $17,361,546$ & 193,895 & 278,214 & 313,900 & $16,575,537$ & 95.47 \\
\hline 2008 & $23,947,316$ & 219,203 & 389,703 & 439,167 & $22,899,243$ & 95.62 \\
\hline 2009 & $15,265,730$ & 259,827 & 411,292 & 273,597 & $14,321,014$ & 93.81 \\
\hline 2010 & $18,788,351$ & 343,637 & 390,262 & 381,831 & $17,672,621$ & 94.06 \\
\hline 2011 & $27,615,560$ & 413,840 & 533,924 & 719,468 & $25,948,328$ & 93.96 \\
\hline 2012 & $32,697,701$ & 466,381 & 614,188 & 932,874 & $30,684,258$ & 93.84 \\
\hline $\begin{array}{l}2002- \\
2012\end{array}$ & $16,663,940$ & 231,573 & 319,165 & 358,900 & $15,754,302$ & 94.46 \\
\hline
\end{tabular}

\section{Empirical Findings}

In recent decades there has been a declining trend of productivity growth in most of Arabian Gulf countries. This decline is more pronounced in 2010s, though it may have started in the early 2000s. As mentioned above, this study instead of analyzing the slowdown in productivity growth, it attempts to incorporate the rents of an exhaustible resource in productivity growth modeling to avoid any misleading estimates that may result in exhaustible resource-based industry.

This section presents the growth rates of multifactor productivity and output in the Kuwait oil industry using models I and II (Equation 4: Model-I and Equation 5: Model-II) discussed above. Table 2 shows annual (year to year) growth rates of all factors of production in Kuwait oil industry for the period 2003 - 2012. Table 2 also presents the average growth rates of these production factors over three selected time periods.

The annual average growth rate of the output was about $15 \%$ over the period of 2003-2012 compared to $22.6 \%$ over the 2003-2007. For most of the time periods the annual average growth rates of intermediate-inputs were higher than that of the output. Generally speaking, the notion of the diseconomies of scale might have had occurred during the period 2008-2012 as the growth rates of all inputs were higher than the growth rate of the output. This had its impact on the annual average growth rate of the resource's rents as well.

Table 2. Annual growth rates of output and inputs: Kuwait oil industry, $2003-2012$

\begin{tabular}{cccccc}
\hline & & \multicolumn{4}{c}{ Annual Growth Rates } \\
\cline { 3 - 6 } YEAR & Output & Capital Services & Labor & Intermediate- Inputs & Resource \\
& $\mathbf{Q}$ & $\mathrm{K}$ & & M & Rents \\
\hline $\mathbf{2 0 0 3}$ & 0.2367 & 0.5108 & 0.0695 & 0.2023 & 0.2373 \\
$\mathbf{2 0 0 4}$ & 0.2644 & 0.0866 & 0.1328 & 0.3226 & 0.2725
\end{tabular}




\begin{tabular}{cccccc}
$\mathbf{2 0 0 5}$ & 0.3766 & 0.0824 & 0.2352 & 0.4092 & 0.3845 \\
$\mathbf{2 0 0 6}$ & 0.2544 & 0.0771 & -0.0147 & 0.1677 & 0.2630 \\
$\mathbf{2 0 0 7}$ & -0.0010 & 0.1784 & 0.1601 & -0.0149 & -0.0052 \\
$\mathbf{2 0 0 8}$ & 0.2080 & 0.0754 & 0.2698 & 0.2071 & 0.2096 \\
$\mathbf{2 0 0 9}$ & -0.3715 & 0.2034 & 0.0149 & -0.4121 & -0.3906 \\
$\mathbf{2 0 1 0}$ & 0.1318 & 0.2202 & -0.0965 & 0.2920 & 0.1344 \\
$\mathbf{2 0 1 1}$ & 0.3354 & 0.1776 & 0.2655 & 0.5845 & 0.3343 \\
$\mathbf{2 0 1 2}$ & 0.1613 & 0.0869 & 0.1086 & 0.2675 & 0.1600 \\
\hline $\mathbf{2 0 0 3 - 2 0 0 7}$ & $\mathbf{0 . 2 2 6 2}$ & $\mathbf{0 . 1 8 7 1}$ & $\mathbf{0 . 1 1 6 6}$ & $\mathbf{0 . 2 1 7 4}$ & $\mathbf{0 . 2 3 0 4}$ \\
$\mathbf{2 0 0 8 - 2 0 1 2}$ & $\mathbf{0 . 0 9 3 0}$ & $\mathbf{0 . 1 5 2 7}$ & $\mathbf{0 . 1 1 2 5}$ & $\mathbf{0 . 1 8 7 8}$ & $\mathbf{0 . 0 8 9 6}$ \\
$\mathbf{2 0 0 3 - 2 0 1 2}$ & $\mathbf{0 . 1 5 9 6}$ & $\mathbf{0 . 1 6 9 9}$ & $\mathbf{0 . 1 1 4 5}$ & $\mathbf{0 . 2 0 2 6}$ & $\mathbf{0 . 1 6 0 0}$ \\
\hline
\end{tabular}

Table 3 shows the unadjusted and the adjusted annual growth rates of multifactor productivity (MFP) and of factor-intensities (FI) in Kuwait oil industry for the period 2003 - 2012. It is clearly observed from table 3 that the annual average growth rate of output over the time period of 2003-2007 was higher than that in the second time period of 2008-2012.

Table 3. Annual growth rates of output, factor intensities and multifactor productivity, Kuwait oil industry, $2003-2012$

\begin{tabular}{cccccc}
\hline & & \multicolumn{2}{c}{ Factor-Intensities (FI) } & \multicolumn{2}{c}{ Multifactor Productivity (MFP) } \\
\cline { 2 - 6 } YEAR & Output & \multicolumn{1}{c}{ FI } & FI $_{\text {adj }}$ & MFP & MFP $_{\text {adj }}$ \\
\cline { 2 - 6 } & $\mathbf{1}$ & $\mathbf{2}$ & $\mathbf{3}$ & $\mathbf{1 - 2}$ & $\mathbf{1 - 3}$ \\
\hline $\mathbf{2 0 0 3}$ & 0.2367 & 0.4931 & 0.2373 & -0.2564 & -0.0006 \\
$\mathbf{2 0 0 4}$ & 0.2644 & 0.0920 & 0.2666 & 0.1724 & -0.0022 \\
$\mathbf{2 0 0 5}$ & 0.3766 & 0.0916 & 0.3776 & 0.2850 & -0.0010 \\
$\mathbf{2 0 0 6}$ & 0.2544 & 0.0774 & 0.2548 & 0.1771 & -0.0004 \\
$\mathbf{2 0 0 7}$ & -0.0010 & 0.1746 & -0.0011 & -0.1756 & 0.0001 \\
$\mathbf{2 0 0 8}$ & 0.2080 & 0.0809 & 0.2092 & 0.1271 & -0.0011 \\
$\mathbf{2 0 0 9}$ & -0.3715 & 0.1882 & -0.3744 & -0.5596 & 0.0030 \\
$\mathbf{2 0 1 0}$ & 0.1318 & 0.2141 & 0.1334 & -0.0823 & -0.0017 \\
$\mathbf{2 0 1 1}$ & 0.3354 & 0.1888 & 0.3361 & 0.1466 & -0.0008 \\
$\mathbf{2 0 1 2}$ & 0.1613 & 0.0922 & 0.1609 & 0.0691 & 0.0004 \\
\hline $\mathbf{2 0 0 3 - 2 0 0 7}$ & $\mathbf{0 . 2 2 6 2}$ & $\mathbf{0 . 1 8 5 7}$ & $\mathbf{0 . 2 2 7 1}$ & $\mathbf{0 . 0 4 0 5}$ & $\mathbf{- 0 . 0 0 0 8}$ \\
\hline $\mathbf{2 0 0 8 - 2 0 1 2}$ & $\mathbf{0 . 0 9 3 0}$ & $\mathbf{0 . 1 5 2 8}$ & $\mathbf{0 . 0 9 3 0}$ & $\mathbf{- 0 . 0 5 9 8}$ & $\mathbf{0 . 0 0 0 0}$ \\
\hline $\mathbf{2 0 0 3 - 2 0 1 2}$ & $\mathbf{0 . 1 5 9 6}$ & $\mathbf{0 . 1 6 9 3}$ & $\mathbf{0 . 1 6 0 1}$ & $\mathbf{- 0 . 0 0 9 7}$ & $\mathbf{- 0 . 0 0 0 4}$ \\
\hline
\end{tabular}

Chart 1 clearly shows the differences in factor intensities (FI) growth rates due to the incorporation of the resource rents in the input side of the growth accounting model. The empirical results of model-II show a significant fluctuation in the un-adjusted FI growth rates in the Kuwaiti oil industry during the period 2003-2006. The FI growth rate experienced a huge to $9.2 \%$ compared to its high growth rate of $49.31 \%$ in 2003 .

Now we consider the impacts of the resources rents which is the main purpose of this study. Consideration of Hotelling and Ricardian rents has enabled us to identify and measure the impact of the resources depletion on the growth rate of 
MFP. Table 4 presents this impact measure $(\Omega)$ defined above as: $\Omega=\mid$ MFP - MFP $_{\text {adj }} \mid$.

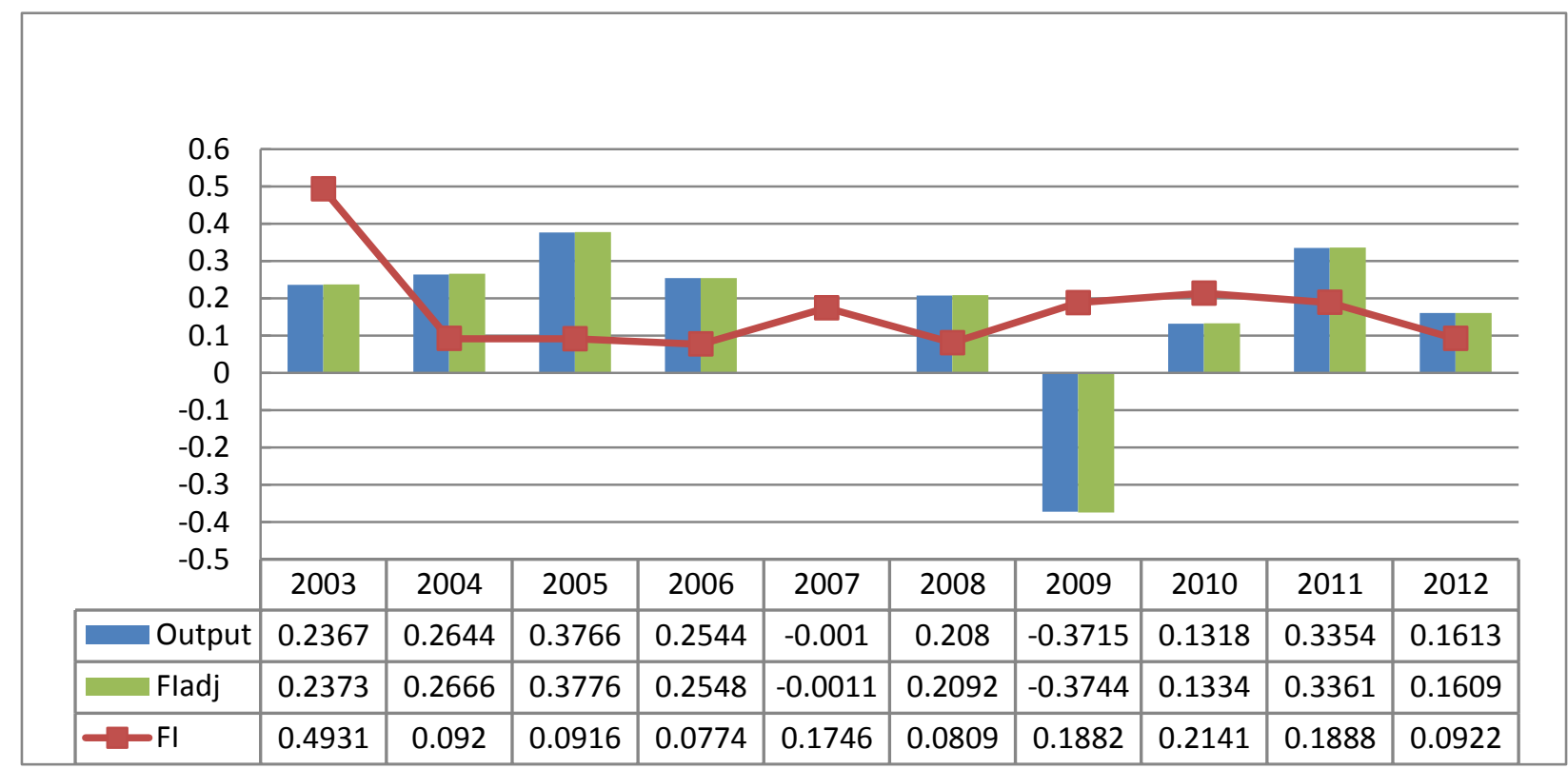

Chart 1. Annual growth rates of output, FI, and FIadj

Table 4. Annual growth rates of multifactor productivity, Kuwait oil industry, $2003-2012$

\begin{tabular}{cccc}
\hline & \multicolumn{2}{c}{ Multifactor Productivity $($ MFP $)$} & Adj. Impact \\
\cline { 2 - 4 } YEAR & MFP & MFP $_{\text {adj }}$ & $\boldsymbol{\Omega}$ \\
\hline $\mathbf{2 0 0 3}$ & -0.2564 & -0.0006 & 0.256 \\
$\mathbf{2 0 0 4}$ & 0.1724 & -0.0022 & 0.175 \\
$\mathbf{2 0 0 5}$ & 0.2850 & -0.0010 & 0.286 \\
$\mathbf{2 0 0 6}$ & 0.1771 & -0.0004 & 0.177 \\
$\mathbf{2 0 0 7}$ & -0.1756 & 0.0001 & 0.176 \\
$\mathbf{2 0 0 8}$ & 0.1271 & -0.0011 & 0.128 \\
$\mathbf{2 0 0 9}$ & -0.5596 & 0.0030 & 0.563 \\
$\mathbf{2 0 1 0}$ & -0.0823 & -0.0017 & 0.081 \\
$\mathbf{2 0 1 1}$ & 0.1466 & -0.0008 & 0.147 \\
$\mathbf{2 0 1 2}$ & 0.0691 & 0.0004 & 0.069 \\
\hline $\mathbf{2 0 0 3 - 2 0 0 7}$ & $\mathbf{0 . 0 4 0 5}$ & $\mathbf{- 0 . 0 0 0 8}$ & $\mathbf{0 . 2 1 3 9}$ \\
\hline $\mathbf{2 0 0 8 - 2 0 1 2}$ & $\mathbf{- 0 . 0 5 9 8}$ & $\mathbf{0 . 0 0 0 0}$ & $\mathbf{0 . 1 8 8 4}$ \\
\hline $\mathbf{2 0 0 3 - 2 0 1 2}$ & $\mathbf{- 0 . 0 0 9 7}$ & $\mathbf{- 0 . 0 0 0 4}$ & $\mathbf{0 . 2 6 6 0}$ \\
\hline
\end{tabular}

Table 4 shows the significance of considering the resource rents in empirical analysis of MFP growth rate. The annual average differences between the growth rates of MFP and $\mathrm{MFP}_{\text {adj }}$ were about $21 \%, 19 \%$, and $27 \%$ over the periods 2003-2007, 2008-2012, and 2003-2012, respectively.

Chart 2 shows the growth rates of MFP and the MFP $_{\text {adj }}$ in Kuwait oil industry. The empirical findings of the two models are significantly different in terms of magnitudes and trends. Results in table 4 (and as shown in chart 2) indicate that the attained growth rate of the unadjusted MFP from model-II would be biased (over/under) estimate of the true MFP growth rate in Kuwait oil industry.

The differences in results of two models reveal the significance of including the resource rents in the inputs said of the 
production function. The empirical findings give evidence and backing to the effectiveness of model-I as an appropriate technique for measuring the multifactor productivity growth in an exhaustible resources extracting industry with a significant resources rents, namely, the Kuwaiti oil industry. It is also important to emphasize that the MFP growth rate of model-I takes into account both Ricardian and Hotelling rents. Moreover, the MFP growth rate obtained from model-I is highly acceptable representation of the performance of the Kuwaiti oil industry.

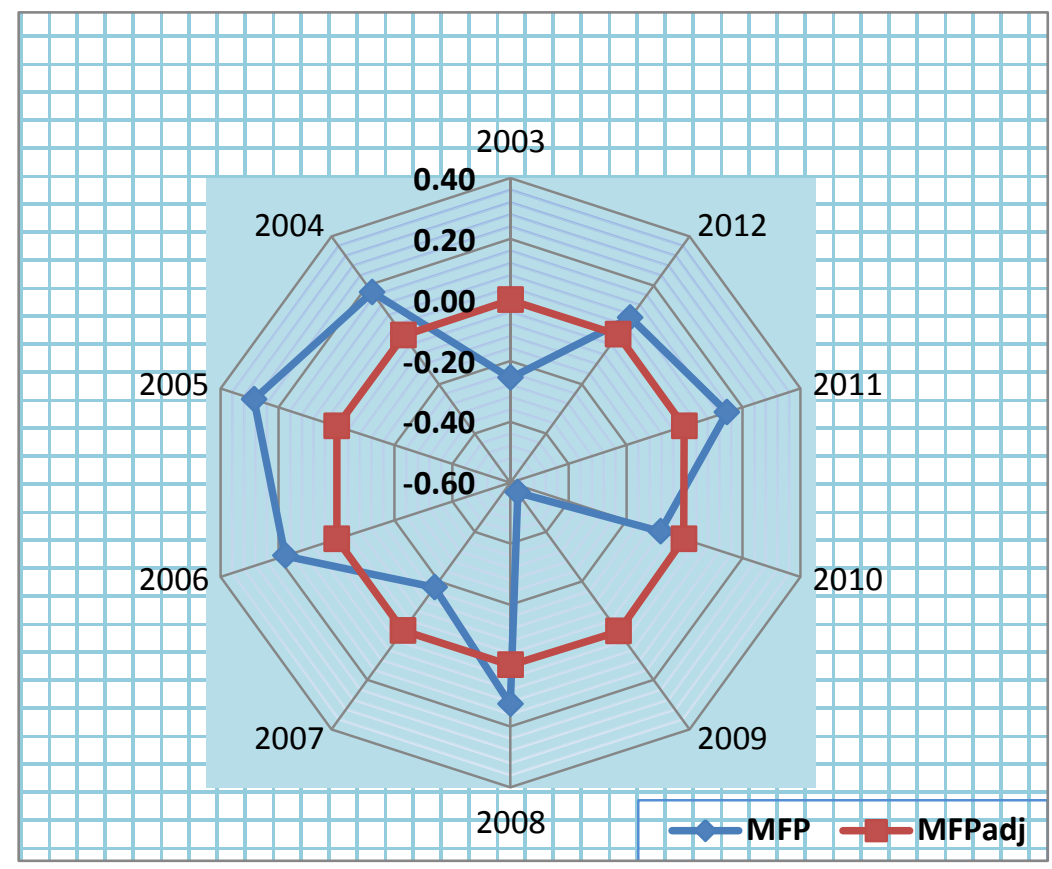

\section{Conclusion}

Chart 2. Annual growth rates of MFP and MFPadj

This study re-examines the notion of incorporating the exhaustible resource (oil) rents in the growth accounting using the Kuwait oil industry for the period 2002 to 2012. That is, it has attempted to answer the question how the incorporation of the exhaustible resource rent could affect the MFP growth rate of an exhaustible resource extracting industry, namely, Kuwait oil industry.

This is done by taking into account the exhaustible resource rents in growth accounting model. By incorporating the resource rents the impact of the resource depletion and land fertility on the growth of MFP was identified and measured for Kuwait oil industry. Considerable different results are obtained using this model (Model I) compared to the results obtained from the classical growth accounting procedures (model II). It follows that an appropriate growth model for an exhaustible resources-based industry (economy) should take into account the total resource rents (scarcity and differential rents) to avoid any miscalculation (inaccuracy) in the growth rate of MFP. This finding confirms the concluding remarks of Al-Ebraheem and Shebeb (1997) and it is recently reiterated by Schreyer et al., (2015) who have stated that failure to account for natural capital may lead to an underestimation of productivity in resource boom.

\section{References}

Al Ebraheem, Y., \& Shebeb, B. (1997). Accounting for growth of total factor productivity and output with exhaustible resource rent: The Kuwaiti oil industry. Journal of Energy and Development, 22(1).

Cairns, R. D. (1986). A model of exhaustible resource exploitation with Ricardian rent. Journal of Environmental Economics and Management, December.

Central Statistical Office. (2004-2012). National Accounts Statistics, Several Issues, Ministry of Planning, Kuwait, 2004-2012.

Central Statistical Office. (2004-2012). Statistical Abstracts, Several Issues, Ministry of Planning, Kuwait, 2005-2012.

Diewert, W. E. (1976). Exact and superlative index numbers. Journal of Econometrics, May 1976.

Diewert, W. E., \& Nakamura, A. (2007). The measurement of aggregate total factor productivity growth. In J. J. Heckman \& E. E. Leamer, (Eds)., Handbook of Econometrics, 4502-4530, Amsterdam: Elsevier Science Publishing. 
Hotelling, H. (1931). The Economics of exhaustible resources. Journal of Political Economy, April 1931.

Jorgenson, D. W. (1971). Divisia index numbers and productivity measurement. Review of Income and Wealth, June 1971.

Miller, E. M. (1992). Ricardian rent, factor quality variations, and the testable implications of production function. Review of Political Economy, October 1992.

Ricardo, D. (1951). The works and correspondence of David Ricard. In P. Svoffa (Eds), The Principles of Political Economy and Taxation, Vol. 1, Cambridge: UK, Cambridge University Press.

Schreyer, P., Brandt, N., \& Zipperer, V. (2015). Productivity measurement with natural capital. Society for Economic Measurement Annual Conference. Paper No. 3, http://repository.cmu.edu/sem_conf/2015/full_schedule/3

Shebeb, B. (2002),. Productivity growth and capacity utilization in the Australian gold mining industry: A short-run cost analysis, Economic Issues, 7(2), 71-81.

\section{Notes}

Note 1. In principle the capital service should represent the current replacement cost of the capital used in the production process. However, in practice, related data were reported as a total depreciation of all fixed assets.

Note 2. Ricardian rent indicates the relative cost advantage of Kuwaiti's oil production to the world's oil production cost. It is reasonable to expect that Kuwait could treat its resource rents as a land payment (Hotelling's rent) reflecting the economic depreciation of its exhaustible resource stocks.

\section{(cc) BY}

This work is licensed under a Creative Commons Attribution 3.0 License. 